REPRODUCTION

\title{
Human reproduction: irrational but in most cases morally defensible
}

\section{R Bennett}

W hile I am inclined to agree that in most cases a choice to become pregnant and bring to birth a child is an irrational choice, unlike Professor Häyry, ${ }^{1}$ I believe that choosing to do so is far from being necessarily immoral. In fact I will argue that it is often these irrational (but morally defensible) choices which make human life the valuable commodity many of us believe it is.

Häyry argues that not only is the choice to have children always an irrational choice, but also it is necessarily an immoral choice. Thus, for Häyry "human reproduction is fundamentally immoral". ${ }^{1}$ He claims it is important to point out to prospective parents that their urge to have children is irrational. From this, he argues, it follows that once this is accepted the use of advance technologies to assist conception should be reassessed, and furthermore, the irrationality and immorality of having children should become a legitimate part of guidance given to those expressing a wish to have children.

According to Häyry the reason it is irrational and immoral to choose to bring to birth a child is that "having a child can always realistically lead to the worse possible outcome, when the alternative is not having a child". ${ }^{1}$ He argues that when people consider having children they are faced with the choice between deciding not to have children and thus harming or benefiting no-one (this, it is argued has a value of zero), or having children where this life may be good or bad, and thus the value of this choice can be negative, positive or zero. ${ }^{1}$ He thus feels that the only rational and moral course of action to avoid suffering where possible is to avoid reproduction as all reproduction involves a risk of suffering.

However, this assertion seems to be far from self-evidently true as it presumes a particularly pessimistic view of the value of human existence. ${ }^{2}$ While it is easy to see how creating a child who is likely to experience great and overwhelming suffering is not only an irrational but also a morally reprehensible choice, ${ }^{3}$ it is not clear that most or even very many children brought to birth will have such an existence. In most cases life is made up of good and bad experiences. If being brought to birth and thus enabled to have the experience of being alive is usually thought to be a valuable and positive experience, then it would seem that unless the child's condition is likely to be so bad that he or she would not have a worthwhile life, a life worth living, then it will always be in that child's interests to be brought into being, and we should enable the creation of this life. It is in the interest of any child whose life will be likely worth living overall, that he or she is brought to birth. It is, after all, that child's only chance of existence. Unless the child is likely to be born with a condition so severe to cause suffering so great as to outweigh the good of life, it is in the interests of an individual to exist despite the possibility of a life compromised by suffering.

However, if it is assumed (as Häyry seems to do so) being brought to birth and enabled to have the experience of being alive is of neutral value then any harms which might be attached to this existence may well make the creation of this life a harm and therefore immoral. As the creation of all human lives involves the creation of unnecessary harm-no life is without suffering - this view does seem to imply that deliberate human procreation is immoral. Or at least the deliberate creation of any life which is likely to involve even a small level of harm is immoral. Not only does this seem to be a rather pessimistic view of human existence but also one that does not seem to be borne out in our experience. Is Häyry really arguing that a life which contains any suffering is a life which should not have been created - that is, it is a worthless life? Surely this would mean that his own life and the lives of those around him are unworthwhile, and that non-existence is a preferable option for himself and others who endure lives that contain suffering even if that suffering is not overwhelming? If Häyry really believes that the morally preferable course of action is one which avoids suffering where this is possible it seems that he should be encouraging not only the avoidance of human reproduction but also the ending of existing human lives including his own.

It appears we can either accept that as all human life contains suffering it should be avoided, or we can take the alternative view that as long as life can be considered generally beneficial rather than generally harmful, creating this life is not immoral. Thus, based on this latter view, as long as the suffering a life contains is likely to be outweighed by positive experiences, choosing to bring such a life into being is morally acceptable, even if the reasons for this choice are irrational.

The irrationality of a choice does not make that choice immoral-many of what are considered to be the most valuable experiences in life, such as love, sex, dancing, creating children, recreational drug/alcohol use, etc, may have little or no rational justification (especially based on Häyry's interpretation of rational) but life without such irrational pleasures and freedoms for many would be unbearable.

For most people planning to conceive and bring to birth children, this choice is necessarily an irrational one. In most cases we choose to bring to birth children on the basis of unquantifiable and unpredictable ideas of what they will bring to our lives and the lives of those around us. Even if we choose to bring to birth children for more pragmatic reasons such as ensuring continuity of the family business or to provide for one's old age it is impossible to determine whether this goal will or is even likely to be achieved. Interestingly, one of the most "rational" reasons which might be given for the decision to bring to birth a child is one that has created great controversy in recent months. The aim of producing a "saviour child", using preimplantation diagnosis and in vitro fertilisation techniques, as a compatible donor for an existing ill child, would seem to be one of very few cases where the choice to create a new child could be viewed as a rational choice. However, most of us create 
children either for no reason at all or to attempt to produce outcomes that can in no way be predicted or guaranteed.

If we truly value an individual's freedom to determine the path of their own lives we should accept the decisions they make even if they appear to have no rational justification. The only justifiable exception to this rule is when the choices of individuals are likely to harm third parties, in which case we maybe justified in intervening to protect the interests of these third parties. If it were clear that most children brought to birth are harmed or wronged by being brought to birth then maybe the choice to have children should be discouraged and not assisted by the state. However, it is not clear if human existence is generally experienced as a harm rather than a benefit even though suffering is necessarily intrinsic to this condition. Thus, where it can be expected that the children created are likely to have worthwhile lives then, however irrational the choices to have these children are, these choices should be respected and enabled (as far as possible) to encourage the flourishing of existing human lives which are enriched by such irrational choices as to bear children, fall in love and other "irrational" human behaviours.

Correspondence to: R Bennett, University of Manchester, Manchester, UK; rebecca.bennett@man.ac.uk

Received 16 July 2003

Accepted for publication 18 July 2003

\section{REFERENCES}

1 Häyry M. A rational cure for pre-reproductive stress syndrome. J Med Ethics 2004;30:377-8.

2 This assertion also focuses purely on the outcome in terms of the welfare of the child who may be created but since Soren Holm deals with this issue in his response to Häyry's paper I will leave this aside for now.

3 See, for example, Rebecca Bennett and John Harris. Are there lives not worth living? When is it morally wrong to reproduce? In: Donna Dickenson, ed. Ethical Issues in Maternal-Fetal Medicine Cambridge, Cambridge University Press, 2002:321-34.

\section{LETTER}

\section{Response from Dundee Medical Student Council to "media misinterpretation"}

We write in response to the original article by Rennie and Rudland published in the April 2003 edition of this journal. ${ }^{1}$ Current and former Dundee Medical School students are concerned at the media misinterpretation of the study and the consequences that this branding of "dishonesty" will have on Dundee Medical School's reputation and also on individuals embarking on their medical careers.

This study was originally published in the $B M J$ in $2001,{ }^{2}$ the data being collected more than two years before that. In the student response to this original study, it was noted that the study had taken place at the time of the introduction of the new curriculum and "students were being asked to produce excessive documentation. Some students did not reference source information properlypartly due to time pressures and partly due to genuine ignorance of proper codes of reference practice". ${ }^{3}$ Further to that, the "scenarios" as described in the published paper, were phrased more ambiguously than the actual scenarios that were used in the questionnaires.

Dundee Medical School took the initial study very seriously. However, they embraced the information from the study in a positive way. Guidelines concerning what was considered fraud and plagiarism in terms of submission of work were established. A code of practice was also developed and this now has to be signed by all medical students on entry to Dundee.

Although much further statistical analysis has been done on this study since that original publication, it still contains all the original raw data. The republishing of this study and the media misinterpretation of it has lead to a whole new generation of Dundee students feeling that they have been marked out as "dishonest" when the Dundee Medical School curriculum has now, and for several years, fully implemented guidelines to guard against any misconduct.

Medical Student Council dundeemsc@hotmail.com

\section{References}

1 Rennie SC, Rudland JR. Differences in medica students' attitudes to academic misconduct and reported behaviour across the years: a questionnaire study. J Med Ethics 2003;29:97-102.

2 Rennie SC, Crosby JR. Are "tomorrow's doctors" honest? Questionnaire study exploring medical students' attitudes and reported behaviour on academic misconduct. BMJ 2001;322:274-5.

3 www.studentbmi.com/back_issues/0501/ letters/160a.html (accessed 20 June 2004). 